\title{
Plesiophysa dolichomastix sp. n. (Gastropoda: Planorbidae)
}

\author{
W Lobato Paraense
}

Departamento de Malacologia, Instituto Oswaldo Cruz-Fiocruz, Av. Brasil 4365, 21045-900 Rio de Janeiro, RJ, Brasil

A new species of planorbid mollusc, Plesiophysa dolichomastix (Greek dolichos $=$ long, mastix $=$ flagellum),

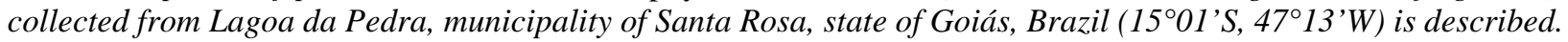
It is indistinguishable by the shell characters from the five congeneric species described so far: P. striata (Orbigny, 1841), P. granulata ("Shuttleworth" Sowerby, 1873), P. guadeloupensis ("Fischer" Mazé, 1883), P. ornata (Haas, 1938) and P. hubendicki Richards \& Ferguson, 1962. It differs from the anatomically studied species in the following characters: about 50 ovotestis diverticula, against 12 in granulata, 100 in ornata, unstated in hubendicki; and length of flagella - about as long as the penial complex -, against about 1/3 to 1/6 in the other three.

Key words: Plesiophysa dolichomastix sp. n. - Mollusca Planorbidae - Central Brazil

In August, 1972, a sample of planorbids collected from Lagoa da Pedra, a lake connected with the river Canabrava, in the municipality of Santa Rosa $\left(15^{\circ} 01^{\prime} \mathrm{S}, 47^{\circ} 13^{\prime} \mathrm{W}\right)$, state of Goiás, included nine empty shells that, on a purely conchological basis (Paraense 1976), was identified as Plesiophysa ornata (Haas 1938). In March, 1975, five live specimens were collected at the same biotope, proving anatomically distinct from P. ornata, as shown below.

\section{METHODS}

The specimens were relaxed for about $8 \mathrm{~h}$ in aqueous solution of $0.05 \%$ nembutal. Then they were immersed for $30 \mathrm{sec}$ in water heated at $70^{\circ} \mathrm{C}$, from which they were transferred to water at room temperature. While under water the animals were drawn from the shell with a small forceps applied to the cephalopedal mass, and fixed in slightly modified Railliet-Henry's fluid (distilled water $930 \mathrm{ml}$, sodium chloride $6 \mathrm{~g}$, formalin $50 \mathrm{ml}$, glacial acetic acid $20 \mathrm{ml}$ ). The radulae were separated from the buccal mass by digestion for $12 \mathrm{~h}$ in a solution of $\mathrm{NaOH}$ at $56^{\circ} \mathrm{C}$. They were then rinsed in tap water and mounted in a drop of glycerin on a microscope slide, with the dorsal (toothed) surface upwards as in the living animal. Measurements were made on camera lucida drawings.

Voucher specimens were deposited in the Malacological Collection of Instituto Oswaldo Cruz (CMIOC-1787, 2041).

\section{DESCRIPTION}

The shell (Figs 1,2) is sinistral, elongato-ovate, translucent, from pale amber to brownish, with four rapidly expanding shouldered whorls separated by a deep suture. Protoconch rounded exserted. Outer whorl exceedingly swollen, as compared with the inner ones. Growth striae closely spaced, crossed by spiral lines, so as to give the shell surface a reticulate appearance. Punctation along the spiral lines represent vestiges of hairy projec-

Fax: +55-21-2280.5840. E-mail: paraense@ioc.fiocruz.br Received 11 October 2001

Accepted 22 November 2001 tions present in young shells (see Paraense 2002, Fig. 2), which may persist in the protected recesses of the suture (Fig. 3). Aperture ovate-deltoid, about 2.5 times longer than the spire. Peristome thin, sharp. Inner lip reflected outward, covering the umbilicus. In some specimens the newly formed and still uncalcified lip has a membranous consistency and shrinks after desiccation (Fig. 2). The largest shell in this sample is $7 \mathrm{~mm}$ long and $4 \mathrm{~mm}$ wide.

The exposed soft parts are light gray, excepting the head and the axis of the tentacles, which are deeply pigmented. The tentacles are slender and very extensible. The foot is oblanceolate.

The roof of the pulmonary cavity is flecked with scattered irregular black spots. Internally (Fig. 4) it is widely occupied by the renal organ, which extends from the left of the heart to the region of the pneumostome; from there it bends on itself to reach the heart auricle, turns again in a sharp curve to descend along the right margin of the previous loop, finally bending leftward to open inside the mantle aperture. A "pericardial organ", described by Harry and Hubendick (1963) in P. granulata, and also present in P. ornata (see Paraense 2002), lies on the right side of the heart. A dorsolateral ridge parallels the left side of the renal organ and reflects ventrally at the back of the pulmonary cavity to proceed cephalad as the rectal ridge.

The jaw (Fig. 5) is T-shaped, as in most planorbid genera. The radular formula of four specimens varied from 171-17 to 24-1-24, with 102 to 118 transverse rows of teeth in the radular ribbon. Fig. 6 shows a series of radular teeth. The salivary glands pass through the nerve ring and are joined to each other behind. The disposition of the digestive organs does not differ substantially from that in other planorbid genera, except for the position of the anterior intestinal loop between the stomach and the albumen gland (Fig. 7). After bending around the stomach and looping superficially over the digestive gland, as usual among planorbids, the intestine proceeds cephalad under the rectal ridge to the anal opening, situated at the dorso-caudal base of a lappet (the anal lobe) under the pseudobranch (Fig. 8). The latter consists of two pleated and highly vascularized lanceolate leaves.

The reproductive system is shown in Fig. 9. The ovotestis consists of about 50 club-shaped diverticula; 

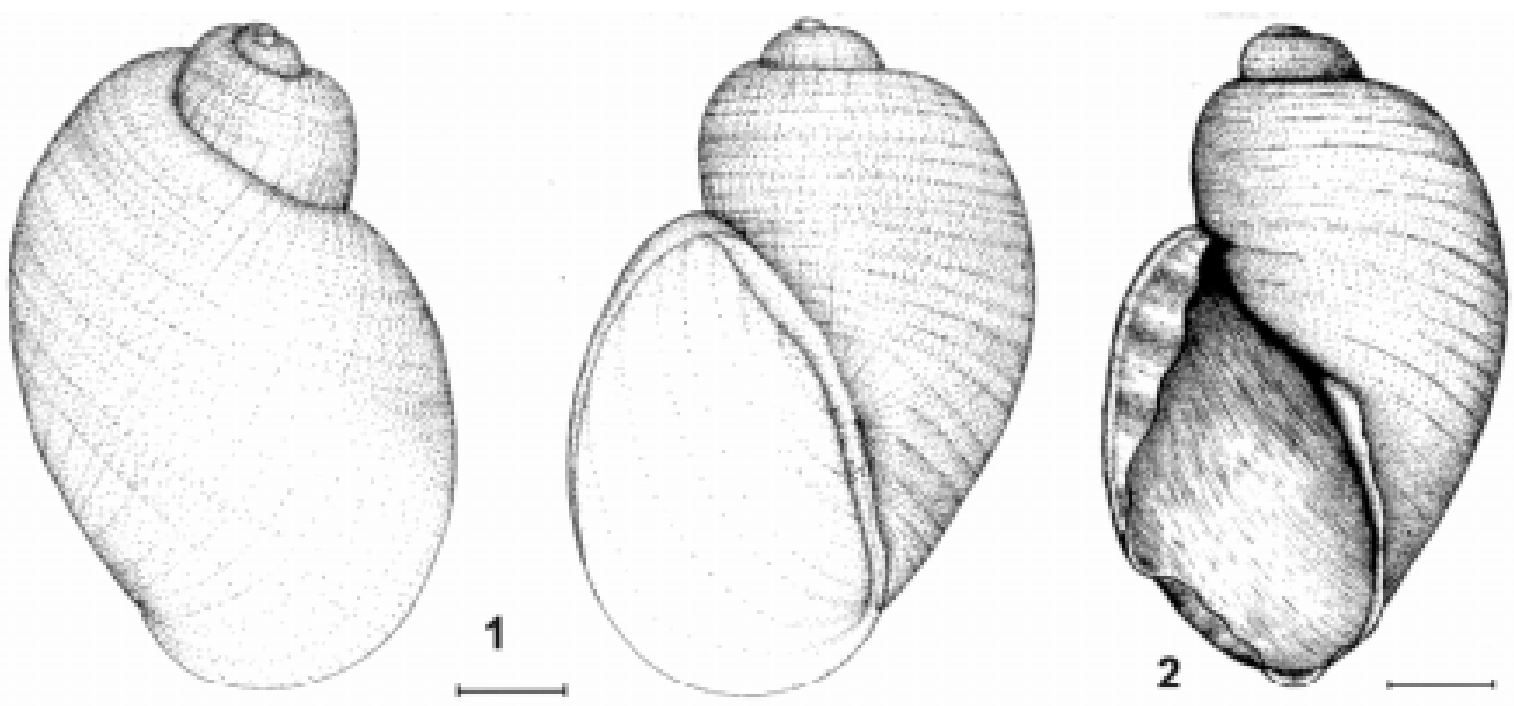

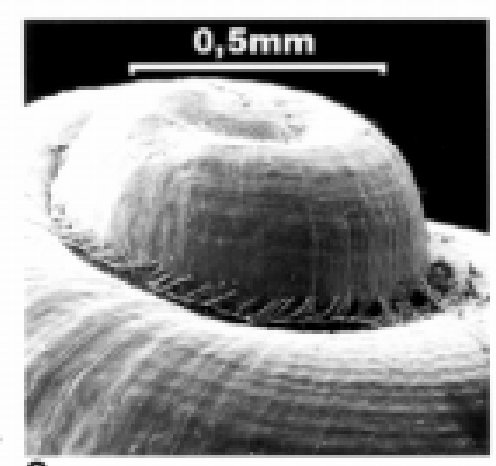

3

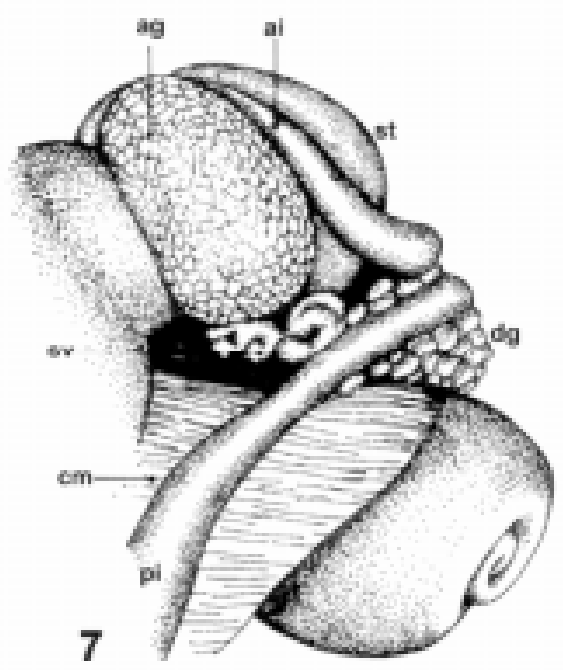

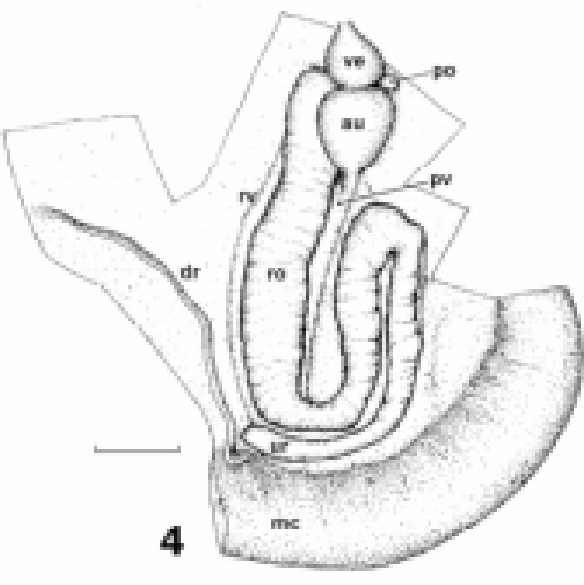
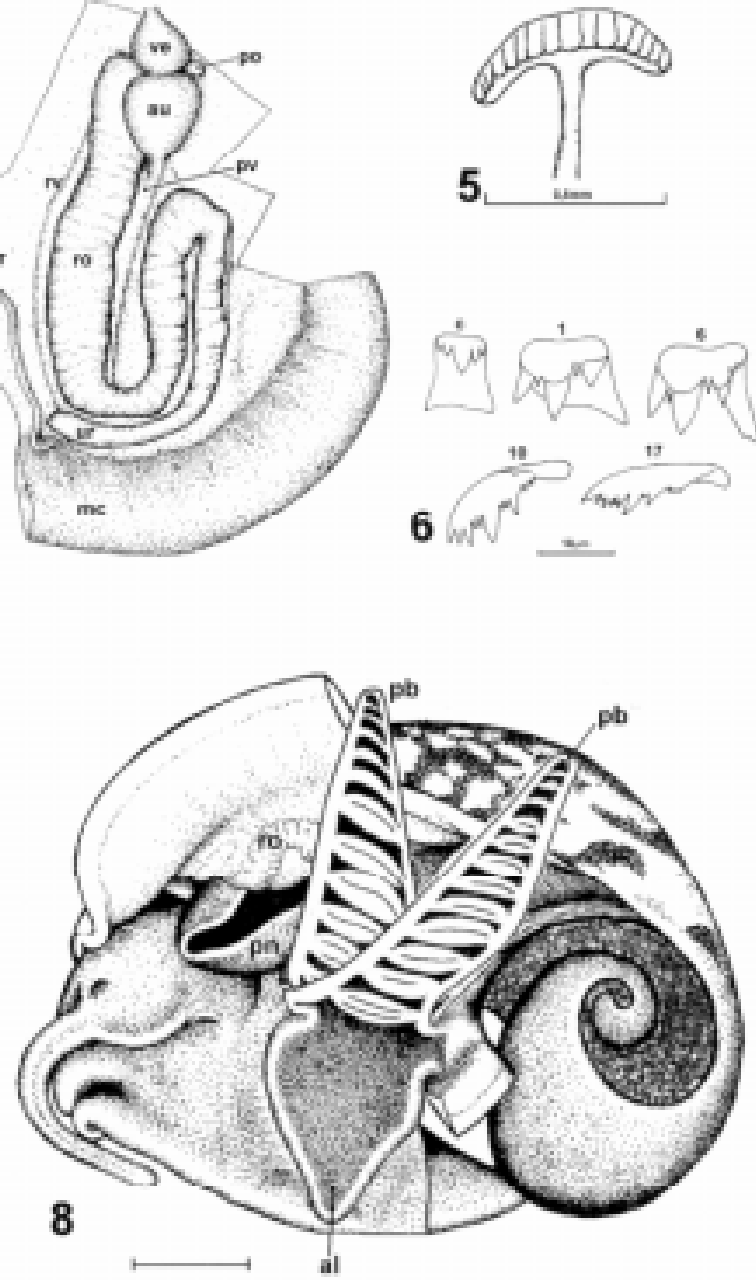

Plesiophysa dolichomastix - Fig. 1: shell. Fig. 2: shell with still uncalcified lip shrunk after desiccation. Fig. 3: SEM showing residual hairy projections confined to suture of a shell. Fig. 4: roof of pulmonary cavity. Fig. 5: jaw. Fig. 6: radular teeth (C: central; 1: lateral; 6, 10: intermediates; 17: marginal). Fig. 7: peristomachic region. Fig. 8: left side of animal partly dissected to show respiratory organs; ag: albumen gland; ai: anterior intestine; al: anal lobe; au: auricle; cm: columellar muscle; dg: digestive gland; dr: dorsal ridge; mc: mantle collar; pb: pseudobranch; pi: posterior intestine; pn: pneumostome; po: pericardial organ; pv: pulmonary vein; ro: renal organ; rv: renal vein; st: stomach; sv: seminal vesicle; ur: ureter; ve: ventricle. Bar $=1 \mathrm{~mm}$ (except Figs 3, 5, 6) 


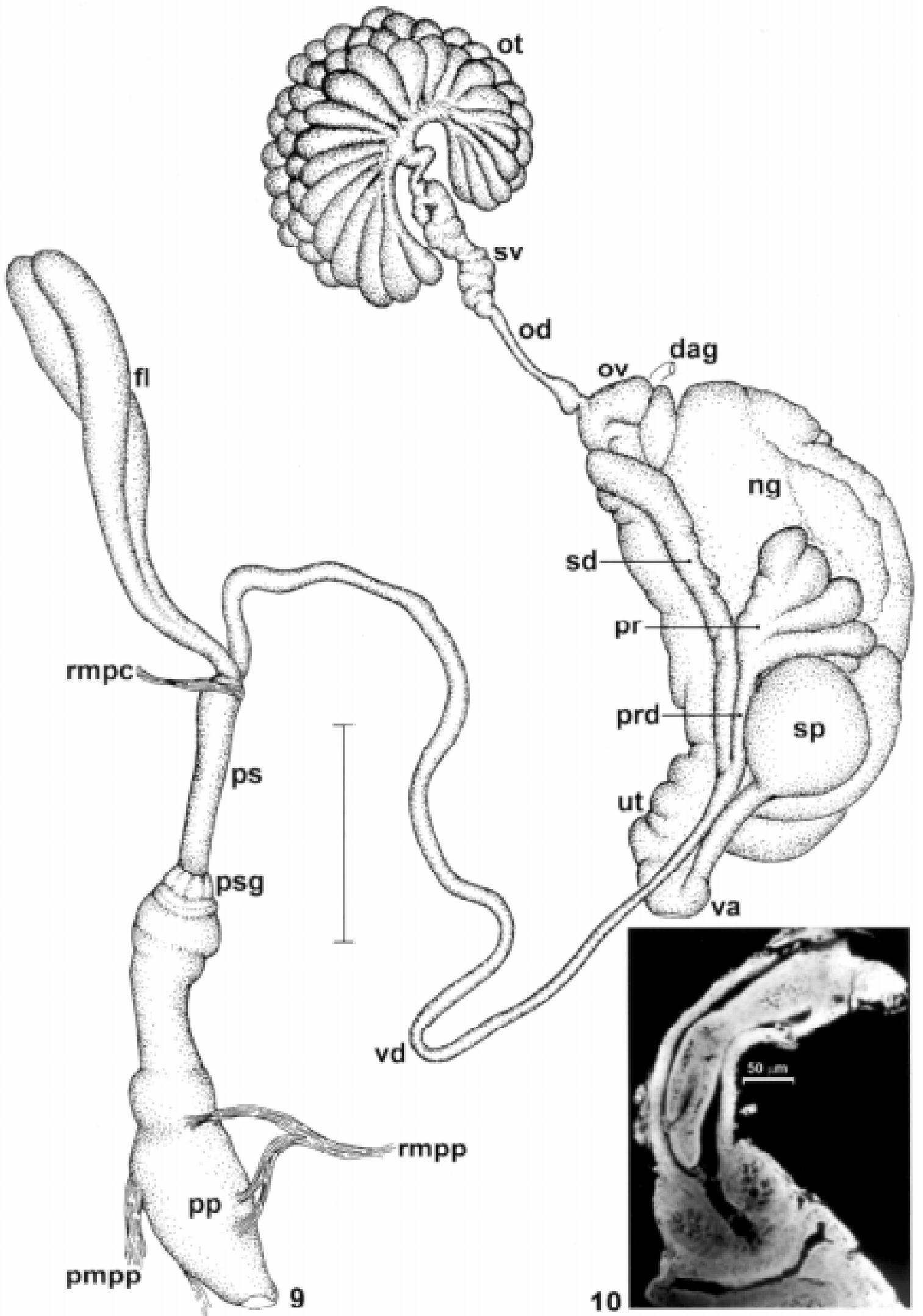

Plesiophysa dolichomastix - Fig. 9: reproductive system. Fig. 10: confocal image of penis inside penial sheath, showing subterminal outlet; dag: duct of albumen gland; fl: flagella; ng: nidamental gland; od: ovispermiduct; ot: ovotestis; ov: oviduct; pmpp: protractor muscle of prepuce; pp: prepuce; pr: prostate; prd: prostate duct; ps: penis sheath; psg: penis sheath gland; rmpc: retractor muscle of penial complex; rmpp: retractor muscle of prepuce; sd: spermiduct; sp: spermatheca; sv: seminal vesicle; ut: uterus; va: vagina; vd: vas deferens. Bar, Fig. $9=1 \mathrm{~mm}$ 
most of them are simple, and a number of bifid or trifid ones are also present. The ovispermiduct and the seminal vesicle show no special features. The oviduct is short and crooked, continuing into a voluminous nidamental gland that suddenly narrows into a convoluted uterus followed by a very short vagina. The spermatheca has a rounded or ovoid body, partly embedded in the wall of the nidamental gland, and a duct about as long as the body emptying near the vaginal opening. The spermiduct extends alongside of the nidamental gland down to the level of the spermatheca. The prostate consists of a few club-shaped, unbranched to trifurcate diverticula (2 to 5 in this small sample), emptying into a separate duct which joins the spermiduct to form the vas deferens. The penial complex is topped by a retractor muscle and two very long flagella (about as long as the penis sheath plus prepuce), which are glandular organs emptying their secretion into the penis sheath. The penis sheath, somewhat shorter than the prepuce, is encircled by eight glands at its distal end, and contains a verge about as long as it, with a subterminal outlet (Fig. 10) and a cuticularized tip. The prepuce, much wider than the penis sheath, is provided with retractor and protractor muscles.

\section{DISCUSSION}

P. dolichomastix is indistinguishable, by the shell characters, from the other known species of the genus, namely, $P$. striata (Orbigny 1841), P. granulata ("Shuttleworth" Sowerby 1873), P. guadeloupensis ("Fischer" Mazé 1883), P. ornata (Haas 1938) and P. hubendicki Richards \& Ferguson 1962.

It differs from the anatomically studied species granulata by Harry and Hubendick (1964), ornata by Hubendick (1949) and Paraense (2002), and hubendicki by Richards and Ferguson (1962) - in the following characters: number of ovotestis diverticula (about 50, against 12 in granulata, 100 in ornata, unstated in hubendicki); and length of flagella (about as long as the penial complex, against about $1 / 3$ to $1 / 6$ in the other three).

Hubendick (1949) describes and figures the prostate diverticula of $P$. ornata as emptying directly into the vas deferens and the penial outlet as terminal. Owing to "the unsatisfactory preservation of the tissues" he "only studied the distal parts of the reproductive organs". By the way, my study (Paraense 2002) of P. ornata involved three samples from the same region as Hubendick's.

\section{ACKNOWLEDGEMENTS}

To Dr Ortrud Monika Barth (Department of Virology) and to Dr Henrique L Lenzi and Thiago B Branquinho (Department of Pathology) for providing the photographs that appear in Figs 3 and 10, respectively. Thanks also to JE Prado, artist of this Department, for preparing the drawings.

\section{REFERENCES}

Haas F 1938. Neue Binnen-Mollusken aus Nordost-Brasilien. Arch Molluskenk 70: 46-51.

Harry HW, Hubendick B 1964. The freshwater pulmonata mollusca of Puerto Rico. Meddelanden Göteborgs Musei Zool Avdelning 136: 1-77.

Hubendick B 1949. The anatomy of Plesiophysa ornata (Haas). Ark Zool 42 A: 1-10.

Mazé H 1883. Catalogue révisé des mollusques terrestres et fluviatiles de la Guadeloupe et de ses dépendances. $J$ Conchyliol 31: 5-54.

Orbigny A 1841. Mollusques, vol I. In Sagra, Histoire physique, politique et naturelle de l'île de Cuba.

Paraense WL 1976. A natural population of Helisoma duryi in Brazil. Malacologia 15: 369-376.

Paraense WL 2002. The genus Plesiophysa, with a redescription of P. ornata (Haas, 1938) (Gastropoda: Planorbidae). Rev Brasil Biol (in press).

Richards CS, Ferguson FF 1962. Plesiophysa hubendicki, a new Puerto Rican planorbid snail. Trans Am Microsc Soc 81: 251-256.

Sowerby Jr GB 1873. Monograph of the genus Physa. In LA Reeve, Conchologia Iconica 19, pl. 8, Figs 64 a-b. 